\title{
Problem Based Learning (PBL) Learning Model Of Indonesian Learning Outcomes For Class II SD Students
}

\section{Nurul Istiqomah}

\author{
SD Negeri Prapag Kidul 03
} istiqomahnurul@gmail.com

\section{Article History}

received 3/12/2020

\begin{abstract}
The aim is to improve learning outcomes of Indonesian language material listening to conversational texts related to culture, sorry. Problem based learning model for second grade elementary school students. This type of research is a class research group, the research subject of teachers and students. Sources of data used are: students, teachers, principals, notes/documents of observations, learning outcomes tests. Data collection techniques with observation (observation), documentation, and tests. The results of this study indicate an increase in Indonesian language learning outcomes. This can be seen from the average value of 76.9 in the first cycle, with a learning completeness percentage of 70\% 16 students who completed their studies. Then there was an increase in the class average score of 82.2 in the second cycle, with a percentage of learning completeness $87 \%$, students who finished learning asthma as many as 20 students. The conclusion is that the problem based learning model can improve learning outcomes of Indonesian language material. Listening to text conversations related to culture, apologize to second grade elementary school students.
\end{abstract}

Keywords: problem based learning, Languages Indonesia

\begin{abstract}
Abstrak
Tujuan untuk meningkatkan hasil belajar materi bahasa indonesia mendengarkan teks percakapan yang berhubungan dengan budaya mohon maaf. Model pembelajaran problem based learning pada siswa kelas II SD. Jenis penelitian ini adalah golongan penelitian kelas, subjek penelitian guru dan siswa. Sumber data yang digunakan adalah : siswa, guru, Kepala Sekolah, catatan/dokumen hasil observasi, tes hasil belajar. Teknik pengumpulan data dengan observasi (pengamatan), dokumentasi, dan tes. Hasil penelitian ini menunjukkan adanya peningkatan hasil belajar bahasa Indonesia. Hal ini dapat dilihat dari nilai rata-rata nilai 76,9 pada siklus I, dengan persentase ketuntasan belajar $70 \% 16$ siswa yang tuntas belajarnya. Kemudian terjadi peningkatan nilai rata-rata kelas sebesar 82,2 pada siklus II, dengan persentase ketuntasan belajar $87 \%$, siswa yang tuntas belajar asmanya sebanyak 20 siswa. Kesimpulan bahwa melalui model pembelajaran problem based learning dapat meningkatkan hasil belajar materi bahasa Indonesia Mendengarkan percakapan teks yang berhubungan dengan budaya mohon maaf pada siswa sekolah dasar kelas dua.
\end{abstract}

Kata kunci: problem based learning, Bahasa Indonesia

Social, Humanities, and Education Studies (SHEs): Conference Series p-ISSN 2620-9284 https://jurnal.uns.ac.id/shes 


\section{PENDAHULUAN}

Pendidikan merupakan salah satu faktor utama bagi pengembangan sumber daya manusia, karena pendidikan diyakini mampu meningkatkan sumber daya manusia sehingga dapat menciptakan manusia produktif yang mampu memajukan bangsanya. Dalam keseluruan proses pendidikan disekolah, kegiatan belajar merupakan kegiatan yang paling pokok. Menurut Sardiman (1994: 95), belajar adalah berbuat. Maksud berbuat ini adalah mengubah tingkah laku menjadi sebuah kegiatan belajar seorang siswa berkaitan dengan tugas guru yaitu mengajar.

Bahasa Indonesia menyediakan berbagai pengalaman belajar bagi siswa untuk memahami konsep, prosess dan menekankan agar siswa menjadi pelajar aktif dan luwes ter hadap pengetahuan. Hal ini berarti bahwa proses belajar mengajar mengajar Bahasa Indonesia tidak hanya berlandaskan pada teori pembelajaran perilaku, tetapi lebih menekankan pada prinsip-prinsip belajar dari teori kognitif. Oleh karena itu tugas guru di kelas tidak sekedar menyampaikan informasi demi pencapaian tujuan pembelajaran, tetapi juga menciptakan pengalaman belajar pada siswa. Berdasarkan observasi awal pada pembelajaran Bahasa Indonesia kelas II SD Negeri Prapag Kidul 03, Hasil belajar siswa rendah, dari 30 siswa dengan nilai KKM (Kriteria Ketuntasan Minimum) 75 , masih $40 \%$ siswa yang nilainya dibawah KKM serta rendahnya motivasi siswa dalam belajar karena pelajaran masih sepenuhnya berpusat pada guru. Untuk mengatasi hal tersebut maka perlu dilakukan proses pembelajaran dengan metode baru yang dapat mengembangkan kemampuan belajar mandiri siwa sehingga dapat meningkatkan pemahaman siswa siswa terhadap materi pelajaran.

Salah satu metode pemelajaran yang dapat mengembangkan kemampuan belajar mandiri adalah metode Problem Based Learning (PBL). PBL memiliki ciri-ciri seperti Amir (2010:12) Pembelajaran dimulai dengan pemberian "masalah", biasanya "masalah" memiliki konteks dengan dunia nyata, pemelajar secara berkelompok aktif merumuskan masalah dan mengidentifikasi kesenjangan pengetahuan mereka, mempelajari dan mencari sendiri materi yang terkait dengan "masalah", dan melaporkan solusi dari "masalah". Dalam metode ini guru menghadapkan siswa pada suatu masalah, kemudian siswa menemukan penyebab dari masalah tersebut, serta menganalisisnya untuk menemukan pengetahuan baru berdasarkan pikiran mereka sendiri.

PTK (Penelitian Tindakan Kelas) merupakan suatu penelitian tindakan yang akar permasalahannya muncul dikelas dan dirasakan langsung oleh guru yang bersangkutan. Dalam PTK, guru secara reflektif dapat menganalisis mensintesisi terhadap apa yang dilakukan dikelas. Dalam hal ini berarti dengan melakukan ptk, pendidik dapat memperbaiki praktik-praktik pembelajaran menjadi efektif.

Berdasarkan latar belakang diatas maka penulis melakukan suatu penelitian berupa Penelitian Tindakan Kelas yang bertujuan hasil belajar Bahasa Indonesia siswa pada materi Mendengarkan teks percakapan yang berhubungan dengan budaya minta maaf.melalui metode Problem Based Learning.

\section{METODE}

Penelitian Tindakan Kelas(PTK) dilaksanakan pada siswa kelas II SD Negeri Prapag Kidul 03 Kecamatan Losari Kabupaten Brebes tahun pelajaran 2020/2021. Waktu penelitian dilaksanakan pada akhir semester II tahun pelajaran 2020/2021 yaitu pada bulan juni 2021 sampai dengan bulan Juli 2021.Sedangkan subjek penelitian ini adalah guru dan siswa kelas II SD berjumlah 23 anak, terdiri dari 10 siswa perempuan dan 13 siswa laki-laki serta guru kelas.

Penelitian ini merupakan Penelitian Tindakan Kelas (PTK) yang dilakukan melalui proses kerja kolaborasi dengan guru, kepala sekolah dan peneliti. Sebagai tahap awal peneliti mencantumkan tujuan penelitian,permasalahan penelitian,dan merencanakan tindakan. Rencana yang telah disusun dilaksanakan peneliti hadir didalam kelas untuk mengamati dan mencatat segala sesuatu yang terjadi pada saat pembelajaran dan 
mencapi tujuan yang telah ditentukan. Metode pengumpulan data yang digunakan adalah sebagai berikut :

1. Observasi adalah teknik pengumpulan data dengan cara melakukan pengamatan. Observasi pada penelitian ini dimaksudkan untuk mengetahui aktivitas siswa kelas II SD Negeri Prapag Kidul 03 dalam pembelajaran Bahasa Indonesia.

2. Dokumentasi ini dikerjakan dengan alat bantu berupa kamera untuk mengabadikan media-media benda konkret dan aktivitas pembelajaran Bahasa Indonesia siswa dalam proses pembelajaran.

3. Tes adalah teknik pengumpulan data dengan cara memberikan sejumlah item soal kepada subjek penelitian.Pada penelitian ini metode tes digunakan untuk mengumpulkan data mengenai hasil belajar siswa.

4. Ada tiga macam wawancara,yakni wawancara baku dan terjadwal,wawancara baku dan tidak terjadwal,serta wawancara tidak baku.

\section{HASIL DAN PEMBAHASAN}

Tabel 1. Data kondisi sebelum tindakan

\begin{tabular}{|c|c|c|c|}
\hline Nama Siswa & $\begin{array}{l}\text { Nilai } \\
\text { KKM }\end{array}$ & $\begin{array}{c}\text { Nilai } \\
\text { Sebelum } \\
\text { Tindakan }\end{array}$ & $\begin{array}{l}\text { Keterangan } \\
\text { Ketuntasan }\end{array}$ \\
\hline 1. Abi Ardiyansyah & 70 & 100 & Tuntas \\
\hline 2. Amalia & 70 & 70 & Tuntas \\
\hline 3. Anugrah Nahil Praditu & 70 & 80 & Tuntas \\
\hline 4. Bahauddin Naqsyabandi & 70 & 60 & Belum tuntas \\
\hline 5. Biyan Angga Devano & 70 & 60 & Belum tuntas \\
\hline 6. Chendi Adi Firmansyah & 70 & 80 & Tuntas \\
\hline 7. Daffa Ijlal Ihtisyam & 70 & 80 & Tuntas \\
\hline 8. Deffany Talita & 70 & 90 & Tuntas \\
\hline 9. Diofa Vixi Alfarel & 70 & 70 & Tuntas \\
\hline 10. Duwi Pratama & 70 & 50 & Belum tuntas \\
\hline 11. Fadil Hafis Ikhsan & 70 & 90 & Tuntas \\
\hline 12. Fuzi Yaningsih & 70 & 80 & Tuntas \\
\hline 13. Gian Aditya Ardhani & 70 & 40 & Belum tuntas \\
\hline 14. Hamdan Abia Akil & 70 & 100 & Tuntas \\
\hline
\end{tabular}




\begin{tabular}{|c|c|c|c|}
\hline 15. Hanin Azzahra & 70 & 80 & Tuntas \\
\hline 16. Hasna Nabilah Fatin & 70 & 50 & Belum tuntas \\
\hline $\begin{array}{l}\text { 17. Hawa Nida Karimah } \\
\text { Wicaksono }\end{array}$ & 70 & 40 & Belum tuntas \\
\hline 18. Imran Khan Islami & 70 & 50 & Belum tuntas \\
\hline 19 Izzan Al Hafiz & 70 & 100 & Tuntas \\
\hline 20. Jahra Feliana Putri & 70 & 50 & Belum tuntas \\
\hline 21 Kusuma Dewi Ayu Lestari & 70 & 40 & Belum tuntas \\
\hline 22. Linsy Azzalfa & 70 & 40 & Belum tuntas \\
\hline 23. Lusi Azizah & 70 & 90 & Tuntas \\
\hline
\end{tabular}

Tabel 2. Kondisi awal hasil belajar Bahasa Indonesia materi Mendengarkan teks percakapan yang berhubungan dengan budaya minta maaf

\begin{tabular}{llc}
\hline \multicolumn{2}{c}{ Sebelum Tindakan } \\
\hline No & \multicolumn{1}{c}{ Hasil belajar } & Hasil yang diperoleh \\
\hline \multicolumn{3}{l}{ Ketuntasan belajar siswa } \\
$\quad$ a. Nilai tertinggi & 400 \\
& b. Nilai terendah & $13(56,5 \%)$ \\
& Ketuntasan kelas & $10(43,4 \%)$ \\
& a. Ketuntasan belajar (nilai $\geq 75)$ & 69,1 \\
& a. Tidak tuntas balajar (nilai $<75)$ & \\
& Nilai rata-rata &
\end{tabular}

Tabel 3. Data Hasil Belajar Siswa Siklus I

\begin{tabular}{clccc}
\hline No & \multicolumn{1}{c}{ Nama Siswa } & NilaiKKM & $\begin{array}{c}\text { Nilai Sebelum } \\
\text { Tindakan }\end{array}$ & $\begin{array}{c}\text { Tindakan kelas } \\
\text { siklus I }\end{array}$ \\
\hline 1. & Abi Ardiyansyah & 70 & 100 & Tuntas \\
2. & Amalia & 70 & 80 & Tuntas \\
3. $\quad \begin{array}{l}\text { Anugrah Nahil } \\
\quad \text { Praditu }\end{array}$ & 70 & 80 & Tuntas \\
\hline
\end{tabular}


SHEs: Conference Series 3 (4) (2020) 562 - 572

\begin{tabular}{|c|c|c|c|c|}
\hline 4. & $\begin{array}{l}\text { Bahauddin } \\
\text { Naqsyabandi }\end{array}$ & 70 & 70 & Tuntas \\
\hline 5. & Biyan Angga Devano & 70 & 70 & Tuntas \\
\hline 6. & $\begin{array}{l}\text { Chendi Adi } \\
\text { Firmansyah }\end{array}$ & 70 & 80 & Tuntas \\
\hline 7. & Daffa ljlal Ihtisyam & 70 & 90 & Tuntas \\
\hline 8. & Deffany Talita & 70 & 100 & Tuntas \\
\hline 9. & Diofa Vixi Alfarel & 70 & 80 & Tuntas \\
\hline 10. & Duwi Pratama & 70 & 60 & Belum tuntas \\
\hline 11. & Fadil Hafis Ikhsan & 70 & 100 & Tuntas \\
\hline 12. & Fuzi Yaningsih & 70 & 90 & Tuntas \\
\hline 13. & Gian Aditya Ardhani & 70 & 50 & Belum tuntas \\
\hline 14. & Hamdan Abia Akil & 70 & 100 & Tuntas \\
\hline 15. & Hanin Azzahra & 70 & 90 & Tuntas \\
\hline 16. & Hasna Nabilah Fatin & 70 & 70 & Tuntas \\
\hline 17. & $\begin{array}{l}\text { Hawa Nida Karimah } \\
\text { Wicaksono }\end{array}$ & 70 & 50 & Belum tuntas \\
\hline 18. & Imran Khan Islami & 70 & 60 & Belum tuntas \\
\hline 19 & Izzan Al Hafiz & 70 & 100 & Tuntas \\
\hline 20. & Jahra Feliana Putri & 70 & 60 & Belum tuntas \\
\hline 21 & $\begin{array}{l}\text { Kusuma Dewi Ayu } \\
\text { Lestari }\end{array}$ & 70 & 50 & Belum tuntas \\
\hline 22. & Linsy Azzalfa & 70 & 50 & Belum tuntas \\
\hline 23. & Lusi Azizah & 70 & 90 & Tuntas \\
\hline
\end{tabular}

Tabel 4. Hasil Belajar Bahasa Indonesia Siklus I

Siklus I

\begin{tabular}{ccc}
\hline No & Hasil belajar & Hasil yang diperoleh \\
\hline 1 & Ketuntasan belajar siswa &
\end{tabular}


c. Nilai tertinggi

d. Nilai terendah

Ketuntasan kelas

2

b. Ketuntasan belajar (nilai $\geq 75$ )

$16(70 \%)$

b. Tidak tuntas balajar (nilai < 75)

$7(30 \%)$

$3 \quad$ Nilai rata-rata

76,9

Tabel 5. Data Hasil belajar siswa siklus II

\begin{tabular}{|c|c|c|c|}
\hline No & Nama Siswa & Nilai KKM & $\begin{array}{c}\text { Tindakan kelas } \\
\text { siklus II }\end{array}$ \\
\hline 1. & Abi Ardiyansyah & 70 & 100 \\
\hline 2. & Amalia & 70 & 80 \\
\hline 3. & Anugrah Nahil Praditu & 70 & 90 \\
\hline 4. & Bahauddin Naqsyabandi & 70 & 70 \\
\hline 5. & Biyan Angga Devano & 70 & 70 \\
\hline 6. & Chendi Adi Firmansyah & 70 & 90 \\
\hline 7. & Daffa ljlal Ihtisyam & 70 & 90 \\
\hline 8. & Deffany Talita & 70 & 100 \\
\hline 9. & Diofa Vixi Alfarel & 70 & 80 \\
\hline 10. & Duwi Pratama & 70 & 80 \\
\hline 11. & Fadil Hafis Ikhsan & 70 & 100 \\
\hline 12. & Fuzi Yaningsih & 70 & 90 \\
\hline 13. & Gian Aditya Ardhani & 70 & 60 \\
\hline 14. & Hamdan Abia Akil & 70 & 100 \\
\hline 15. & Hanin Azzahra & 70 & 90 \\
\hline 16. & Hasna Nabilah Fatin & 70 & 80 \\
\hline \multirow[t]{2}{*}{17.} & Hawa Nida Karimah & 70 & 70 \\
\hline & Wicaksono & & \\
\hline 18. & Imran Khan Islami & 70 & 70 \\
\hline
\end{tabular}




\begin{tabular}{llcc}
\hline 19 & Izzan Al Hafiz & 70 & 100 \\
20. & Jahra Feliana Putri & 70 & 60 \\
21 & Kusuma Dewi Ayu & 70 & 50 \\
& Lestari & & \\
22. & Linsy Azzalfa & 70 & 70 \\
23. Lusi Azizah & 70 & 100 \\
\hline
\end{tabular}

Tabel 6. Hasil Belajar Bahasa Indonesia Siklus II

\begin{tabular}{llc}
\hline \multicolumn{1}{c}{ Hasil Belajar } & Siklus II \\
\hline No & \multicolumn{1}{c}{ Hasil yang diperoleh } \\
\hline $1 \quad$ & Ketuntasan belajar siswa & 100 \\
& a. Nilai tertinggi & 50 \\
& b. Nilai terendah & \\
2 & Ketuntasan kelas & $20(87 \%)$ \\
& a. Ketuntasan belajar (nilai $\geq 75)$ & $3(13 \%)$ \\
& b. Tidak tuntas belajar (nilai $<75)$ & 82,2 \\
\hline & Nilai rata-rata &
\end{tabular}

Data hasil belajar siswa kelas II SD Negeri Prapag Kidul 03 dalam pembelajaran Bahasa Indonesia materi Mendengarkan teks percakapan yang berhubungan dengan budaya minta maaf dari sebelum tindakan kelas sampai dengan siklus II dalam bentuk tabel berikut ini :

Tabel 6. Hasil Belajar Siswa

\begin{tabular}{|c|c|c|c|c|}
\hline No & Hasil belajar & $\begin{array}{c}\text { Sebelum } \\
\text { Tindakan }\end{array}$ & Siklus I & Siklus II \\
\hline \multirow[t]{3}{*}{1} & Ketuntasan belajar siswa & & & \\
\hline & a. Nilai tertinggi & 100 & 100 & 100 \\
\hline & b. Nilai terendah & 40 & 50 & 50 \\
\hline 2 & Nilai rata-rata & 69,1 & 76,9 & $\begin{array}{c}82 \\
2\end{array}$ \\
\hline
\end{tabular}


Adapun Perbandingan peningkatan hasil belajar Bahasa Indonesia kelas II SD Negeri Prapag Kidul 03 dalam pembelajaran Bahasa Indonesia dari sebelum tindakan kelas sampai dengan tindakan kelas Siklus II sebagia berikut:

Tabel 7. Data Perbandingan Hasil Belajar Siswa

\begin{tabular}{|c|c|c|c|c|c|}
\hline No & Nama Siswa & $\begin{array}{l}\text { Nilai } \\
\text { KKM }\end{array}$ & $\begin{array}{l}\text { Nilai Sebelum } \\
\text { Tindakan }\end{array}$ & $\begin{array}{c}\text { Tindakan } \\
\text { kelasSiklus I }\end{array}$ & $\begin{array}{c}\text { Tindakan } \\
\text { kelasSiklus } \\
\text { II }\end{array}$ \\
\hline 1. & Abi Ardiyansyah & 70 & 100 & 100 & 100 \\
\hline 2. & Amalia & 70 & 70 & 80 & 80 \\
\hline \multirow[t]{2}{*}{3.} & Anugrah Nahil & 70 & 80 & 80 & 90 \\
\hline & Praditu & & & & \\
\hline \multirow[t]{2}{*}{4.} & Bahauddin & 70 & 60 & 70 & 70 \\
\hline & Naqsyabandi & & & & \\
\hline \multirow[t]{2}{*}{5.} & Biyan Angga & 70 & 60 & 70 & 70 \\
\hline & Devano & & & & \\
\hline \multirow[t]{2}{*}{6.} & Chendi Adi & 70 & 80 & 80 & 90 \\
\hline & Firmansyah & & & & \\
\hline \multirow[t]{2}{*}{7.} & Daffa Ijlal & 70 & 80 & 90 & 90 \\
\hline & Ihtisyam & & & & \\
\hline 8. & Deffany Talita & 70 & 90 & 100 & 100 \\
\hline 9. & Diofa Vixi Alfarel & 70 & 70 & 80 & 80 \\
\hline 10. & Duwi Pratama & 70 & 50 & 60 & 80 \\
\hline 11. & Fadil Hafis Ikhsan & 70 & 90 & 100 & 100 \\
\hline 12. & Fuzi Yaningsih & 70 & 80 & 90 & 90 \\
\hline \multirow[t]{2}{*}{13.} & Gian Aditya & 70 & 40 & 50 & 60 \\
\hline & Ardhani & & & & \\
\hline 14. & Hamdan Abia Akil & 70 & 100 & 100 & 100 \\
\hline 15. & Hanin Azzahra & 70 & 80 & 90 & 90 \\
\hline \multirow[t]{2}{*}{16.} & Hasna Nabilah & 70 & 50 & 70 & 80 \\
\hline & Fatin & & & & \\
\hline
\end{tabular}




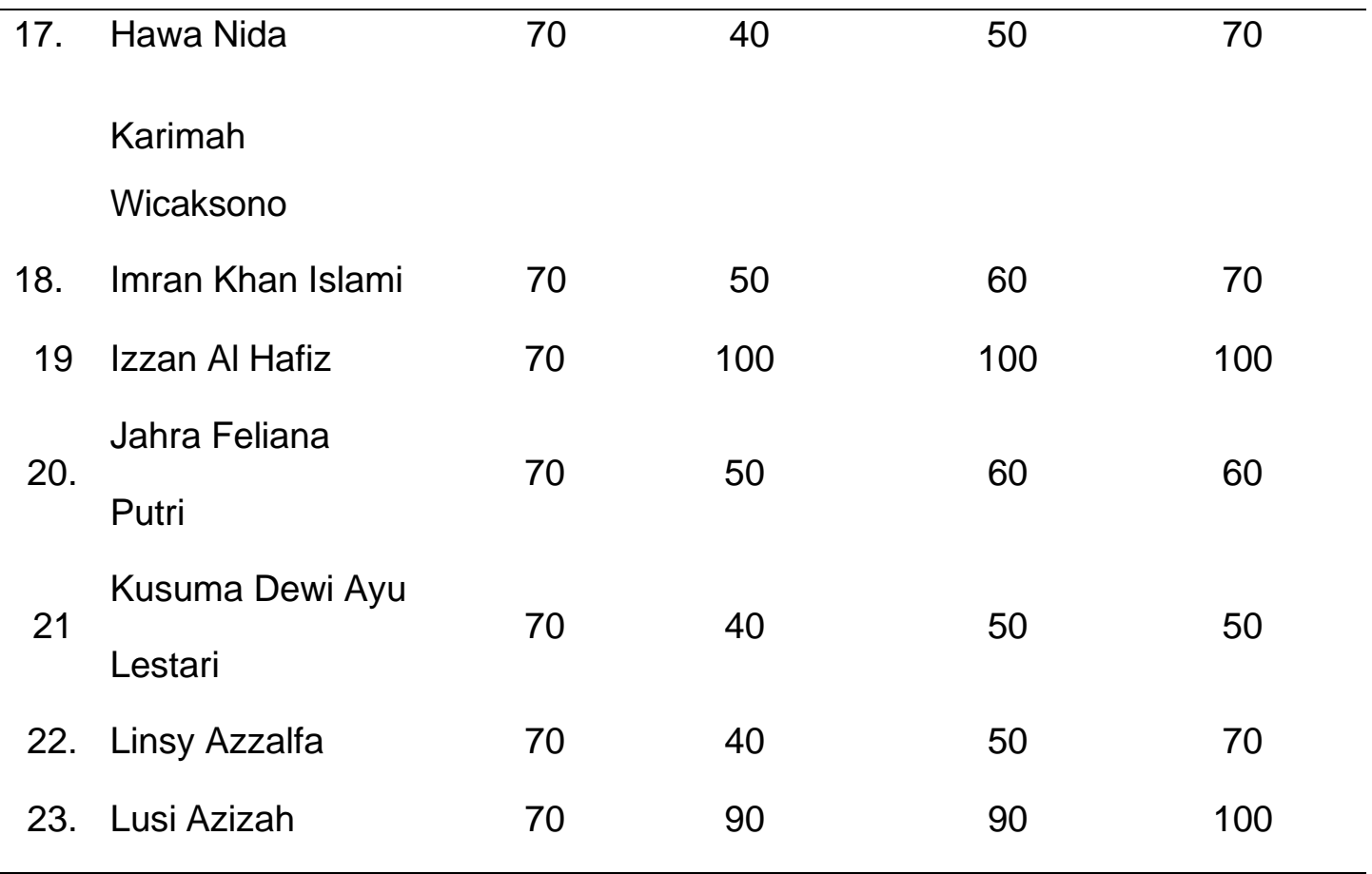

Data yang diperoleh mengenai ketuntasan hasil belajar siswa dalam pembelajaran Bahasa Indonesia melalui model pembelajaran problem based learning adalah sebagai berikut :

Tabel 8. Ketuntasan Belajar Siswa

\begin{tabular}{ccccc}
\hline No & Ketuntasan belajar & $\begin{array}{c}\text { Sebelum } \\
\text { Tindakan }\end{array}$ & Siklus I & Siklus II \\
\hline 1 & Ketuntasan belajar (nilai $\geq 75)$ & $18(60 \%)$ & $\begin{array}{c}22 \\
(73,3 \%)\end{array}$ & $26(86,7 \%)$ \\
& & & $8(26,7 \%)$ & $4(13,3 \%)$ \\
\hline
\end{tabular}

Hasil belajar siswa dapat diketahui dari sebelum diadakan tindakan hanya sedikit siswa yang mendapatkan hasil belajar diatas nilai KKM. Hal ini disebabkan setiap anak yang memiliki angapan bahwa pelajaran Bahasa Indonesia itu sulit untuk dipelajari karena berisi istilah-istilah asing, sehingga hasil yang diperoleh kurang maksimal dan nilai dibawah KKM. Kemampuan pemahaman siswa mulai mengalami peningkatan pada siklus I. Pembelajaran yang dirancang dengan menerapkan model pembelajaran problem based learning mampu meningkatkan hasil belajar siswa dalam Bahasa Indonesia materi Mendengarkan teks percakapan yang berhubungan dengan budaya minta maaf.

Tindakan kelas siklus I diperoleh dengan nilai terendah 50 dan nilai tertinggi 100 . Ketuntasan belajar (nilai $\geq 70$ ) sebanyak 16 siswa, tidak tuntas belajar (nilai $<70$ ) sebanyak 7 siswa, nilai rata-rata kelas 76,9. Data menunjukkan bahwa kemampuan siswa yang terlihat dalam hasil belajar Bahasa Indonesia siswa materi Mendengarkan teks percakapan yang berhubungan dengan budaya minta maaf belum mengalami peningkatan yang signifikan.

Tindakan kelas siklus II siswa semakin meningkat, hal ini disebabkan siswa mulai tertarik dan siswa ikut mulai terbiasa serta ikut berpartisipasi aktif dalam pembelajaran dikelas. Pada tindakan kelas siklus II ini diperoleh nilai terendah 50 dan nilai tertinggi 
100. Ketuntasan belajar (nilai $\geq 70$ ) sebanyak 20 siswa, tidak tuntas belajar (nilai $<70$ ) sebanyak 3 siswa, nilai rata-rata kelas 82,2. Data ini menunjukkan peningkatan yang lebih signifikan dari siklus I. Hal ini disebabkan karena siswa diberi kebebasan berpendapat serta dalam mengerjakan soal Bahasa Indonesia materi Mendengarkan teks percakapan yang berhubungan dengan budaya minta maaf.

Ketuntasan kelas adalah berapa banyak siswa yang memperoleh nilai minimal keberhasilan siswa yaitu dengan nilai $\geq 70$. semakin banyak siswa yang mencapai nilai ketuntasan setelah dilakukan pembelajaran melalui model problem based learning.

Ketuntasan kelas sebelum tindakan diperoleh data dari 23 siswa ada 13 siswa $(56,5 \%)$ dan tidak tuntas ada 10 siswa $(43,4 \%)$ siswa. Pada siklus I diperoleh ketuntasan kelas sebanyak 16 siswa (70\%), tidak tuntas 7 siswa (30\%), pada siklus II diperoleh ketuntasan kelas sebanyak 20 siswa (87\%), tidak tuntas 3 siswa (13\%). Tindak mengajar

pada pembelajaran Bahasa Indonesia materi Mendengarkan teks percakapan yang berhubungan dengan budaya minta maaf. Tindakan belajar yang dilakukan siswa pada setiap pertemuan mengalami perubahan kearah yang lebih baik, siswa lebih aktif dalam mengikuti pembelajaran dan tidak merasa bosan selama proses pembelajaran berlangsung. Melalui pembelajaran problem based learning ini menjadikan siswa lebih berpartisipasi aktif memecahkan kesulitan yang dialami siswa selama proses belajar Bahasa Indonesia di kelas. Dalam pembelajaran Bahasa Indonesia materi Mendengarkan teks percakapan yang berhubungan dengan budaya minta maaf guru menerapkan model pembelajaran problem based learning dengan tepat dan benar sehingga hasil belajar akan meningkat. Dari pembahasan di atas menunjukkan bahwa indikator keberhasilan tercapai, adanya peningkatan hasil belajar siswa dalam kegiatan pembelajaran dikelas dengan menggunakan model pembelajaran problem based learning materi Mendengarkan teks percakapan yang berhubungan dengan budaya minta maaf pada siswa kelas II SD Negeri Prapag Kidul 03 Kecamatan Losari Kabupaten Brebes Tahun Pelajaran 2020/2021.

\section{SIMPULAN}

Hasil belajar siswa dengan nilai rata- rata kelas 76,9 pada siklus I, dengan persentase ketuntasan belajar $70 \%$, siswa yang tuntas dalam pembelajaran sebanyak 16 siswa. Kemudian mengalami peningkatan menjadi 82,2 pada siklus II, dengan persentase ketuntasan belajar mencapai $87 \%$, siswa yang tuntas dalam pembelajaran sebanyak 20 siswa.

Dalam hipotesis menyatakan"adanya peningkatan hasil belajar Bahasa Indonesia siswa kelasll SD Negeri Prapag Kidul 03 Tahun Pelajaran 2020/2021 melalui metode pembelajaran problem based learning (PBL).

Ini dapat disimpulkan bahwa melalui modelpembelajaran Problem Based Learning (PBL) dapat meningkatkan hasil belajar Bahasa Indonesia materi Mendengarkan teks percakapan yang berhubungan dengan budaya minta maaf.pada siswa kelas II SD Negeri Prapag Kidul 03 Kecamatan Losari Kabupaten Brebes Tahun Pelajaran 2020/2021.

\section{DAFTAR PUSTAKA}

Asep J, dan Abdul H, 2012. Evaluasi pembelajaran. Yogyakarta: Multi PersindoAry, Dona Aunurrahman, 2013. Belajar dan pembelajaran.Bandung: Alfabeta

Cipta Arikunto, Suharsimi. 2013. Prosedur Penelitian. Jakarta: Rineka

Cipta Arleli, 2012. Meningkatkan minat belajar pada pembelajaran Bahasa Indonesia Model berfiki kreatif (CreativeThinking Model)

Dimyati, dan Mujiono. 2009. Belajar dan pembelajaran. Jakarta : Rhineka

Grafindo Sastrawati,E.2011. Pengaruh media pembelajaran problem based learning dan Hamalik, O. 2011. proses belajar mengajar. Jakarta : Bumi 
Huda, Miftahul. 2014. Model-model pengajaran dan pembelajaran. Yogyakarta: Pustaka Pelajar.

Kiptiyah, M. 2006. Persepsi siswa tentang bimbingan belajar dan minat belajarserta hubungannya dengan hasil belajar Ekonomi, skripsi. Universitas Jambi. Jambi

Rusman, 2011. Model-model pembelajaran mengembangkan professionalism Guru. Jakarta: Rajawali

Slameto, 2010. Belajar dan faktor-faktor yang mempengaruhi. Jakarta : Rhineka Cipta Sugiyono, 2012.Metode penelitian pendidikan. Bandung: Alfabeta

Sugiyono. 2014. Metode penelitian pendidikan (pendekatan kauntitatif, kualitatif,danR \& D). Bandung: Alfabeta

Trianto, 2014. Mendesain model pembelajaran inovatif, progresif, dan konstekstual.Jakarta:Prenada Media 